\title{
EMBRIONES EN REPRODUCCIÓN HUMANA ASISTIDA: CONTROVERSIAS SOBRE LA CONGELACIÓN Y EL ESTUDIO GENÉTICO PRE-IMPLANTATORIO.
}

\begin{tabular}{llllll} 
EMBRYOS IN ASSISTED & HUMAN & \multicolumn{2}{c}{ REPRODUCTION: } \\
CONTROVERSIES ABOUT THE & FREEZING AND THE PRE- \\
IMPLANTATION GENETIC STUDY. & & &
\end{tabular}

\section{Patricia CRAVIOTTO VALLE}

Resumen: Este estudio pretende un aproximación a la controversia jurídica relativa a la congelación de embriones sobrantes en técnicas de reproducción humana asistida y en conexión al estudio genético pre-implantatorio.

Abstract: This paper aims an approach to juridical controversy around the frozen embryos useless for in vitro techniques and in particular, as regards the pre implantatory genetic study.

Palabras clave: Reproducción humana y embriones - estudio genético pre implantatorio Bioética

Key words: Human reproduction and embryos - pre implantatory genetic study Bioethics-

Para poder analizar en profundidad la situación actual de los embriones en la reproducción asistida, hemos de tener unos mínimos conocimientos históricos previos sobre la misma, que permita situarnos en unos antecedentes que a su vez permitan la comprensión del lector, con mayor rigor acerca de la controversia existente en relación a la congelación ${ }^{1}$ y al estudio genético pre-implantacional ${ }^{2}$.

En julio de 1978 nació por cesárea el primer ser humano por fecundación in vitro: una niña de origen inglés. Ello fue posible gracias a Patrick Steptoe-ginecólogo-, a Robert

\footnotetext{
${ }^{1}$ Los términos congelación o criogenización o crioconservación, han de considerarse equiparables a efectos técnicos en esta investigación.

${ }^{2}$ Pre-implantacional o preimplantacional, son términos que hacen referencia al momento anterior a la implantación del preembrión en el útero materno -como más adelante se detallará-, y en el cual el preembrión es analizado y crioconservado antes de los catorce días, desde la fecundación en laboratorio.
} 
Edwards -fisiólogo- y por supuesto a la perseverancia de sus progenitores. Tan solo tres meses más tarde nació el segundo niño por FIV en la India. Fueron los comienzos de una nueva etapa en la historia del ser humano.

Es destacable el nacimiento de un niño en Virginia -EEUU- en diciembre de 1981, el cual fue posible gracias al uso de hormonas que estimulaban los ovarios, y que pudo llegar a nacer gracias a la técnica FIV. El equipo médico responsable de este logro fueron los doctores Howard y Georgeanna Jones, y fue el primero del mundo con esta aplicación técnica.

En 1983 se produce un hito: el primer bebé nacido a nivel mundial tras un proceso de criopreservación y descongelación de embriones. El asombroso resultado fue posible gracias al equipo de origen australiano dirigido por el embriólogo Alan Osborne Trounson y Mohr. En este mismo año se produjo la publicación del primer bebé nacido gracias a la donación de ovocitos. Doblemente un año especial para la fecundación in vitro mundial.

España se hizo eco de los éxitos que la FIV estaba recolectando en todo el mundo, y así en julio de 1984 nació a las 37 semanas de gestación -en Barcelona- una niña: Victoria Anna. En esta ocasión los responsables del ansiado logro fue el equipo que dirigía el Dr. Pedro Barri junto a la bióloga Anna Veiga del Instituto Universitario Dexeus. El origen in vitro en nuestro país se desarrolló dentro del sistema sanitario privado: el único posible en esos momentos. Pero tan solo un año más tarde -1985-, la medicina pública española consiguió que naciese un niño en un centro de la Seguridad Social en Bilbao: Jose Ángel. El nombre se lo pusieron en honor al Dr. Jose Ángel Portuondo ${ }^{3}$. Ambos nacimientos son el punto de partida de España como un Estado en el que la biomedicina y la ética confluyeron, posibilitando el nacimiento de personas que de no haber sido por esta técnica, hoy no existirían. Una técnica que permitió hacer padres a progenitores con problemas de infertilidad clínica probada.

En el año 1987 -cuatro años más tarde desde el primer logro internacional- en el Instituto Universitario Dexeus se consiguió un primer nacimiento a través de la técnica de

\footnotetext{
${ }^{3}$ Doctor que impulsó por primera vez en la Seguridad Social española, un servicio de fecundación in vitro. No llegó a ver el resultado de su esfuerzo, muriendo unos meses antes de nacer Jose Ángel, en un accidente aéreo.
} 
congelación y descongelación de embriones. Un año más tarde -1988- se consiguieron los primeros nacimientos con donación de ovocitos ${ }^{4}$ en España.

En el 1990 fue publicada por primera vez la aplicación clínica del diagnóstico genético preimplantacional $(D G P)^{5}$, que pudo ver la luz gracias a Handyside, Kontogianni y Winston en el Hospital de Londres.

En España se consigue en 1994 -gracias al Instituto Universitario Dexeus en colaboración con la Universidad Autónoma de Barcelona-, el nacimiento del primer bebé tras un diagnóstico genético preimplantacional que logró seleccionar el sexo del embrión.

En 1995 el Instituto Valenciano de Infertilidad -IVI-, logró el primer embarazo del mundo partiendo de espermatozoides congelados que procedían de testículos. Un gran avance a nivel internacional conseguida gracias a la investigación española.

Tuvimos que esperar al año 2002 en España para que por primera vez nacieran niños tras congelar y descongelar ovocitos. En esta ocasión sería el equipo del Dr. Simón Marina -del Instituto CEFER- el responsable de este nuevo éxito.

Es curiosamente en este mismo año y de nuevo en nuestro país, cuando el IVI -en colaboración con la Universidad Autónoma de Barcelona-, consigue gracias al DGP, que nazca un bebé sano a pesar de que sus padres eran portadores de fibrosis quística ${ }^{6}$.

En el año 2003 se consigue el nacimiento de un bebé sin afección por la enfermedad Corea de Huntigton ${ }^{7}$, gracias al equipo de la Fundación Jiménez Díaz. Y en 2008 se logra el nacimiento de un niño histocompatible ${ }^{8}$ con su hermano, para tratar a este

\footnotetext{
${ }^{4}$ Según la RAE ovocito es "óvulo en diferenciación”. Lo que es lo mismo que la célula femenina producida en el ovario y que permite la germinación de la misma en conexión con un espermatozoide.

${ }^{5}$ El DGP o Diagnóstico Genético Preimplantacional, puede definirse como aquel conjunto de técnicas que permite evaluar si los embriones -que se obtienen por FIV-tienen cromosomas normales o anormales. Es decir, localiza posibles aneuploidías.

${ }^{6} \mathrm{La}$ "fibrosis quística" es una enfermedad genética -hereditaria- que es provocada por un incorrecto funcionamiento de las llamadas glándulas exocrinas, y la cual se caracteriza por presentar disfunciones en el páncreas y enfermedades pulmonares crónicas. Dentro de las enfermedades hereditarias, es actualmente una de las más comunes entre la población.

${ }^{7}$ Corea Huntington es una enfermedad neurológica de las denominadas raras y graves, de carácter hereditaria y degenerativa. Esta enfermedad la detectó por primera vez el doctor estadounidense George Huntigton en el año 1872 .

${ }^{8}$ Según la RAE, "histocompatibilidad" se define como el grado de semejanza de los antígenos tisulares de distintos individuos del que depende la posibilidad de un injerto o trasplante. Dicho de otro modo, la posible
} 
último de una anemia congénita severa ${ }^{9}$. Esta vez hay que agradecer este gran paso a la Unidad de Genética y Reproducción Humana Asistida del Hospital Virgen del Rocío Sevilla-, y en concreto al equipo dirigido por el Dr. Guillermo Antiñolo.

En 2006 el equipo de las doctoras Gemma Arroyo y Rosa Tur, consiguen que nazca el primer bebé en España que se concibe a partir de ovocitos madurados in vitro.

En el año 2007 nacieron los primeros niños en nuestro país tras un proceso de vitrificación de ovocitos gracias al IVI -concretamente al equipo de la Dra. Cobo-, y en 2009 el IVI de Valencia junto con el Hospital Universitario Dr. Peset Aleixandre de Valencia, logró el primer embarazo gracias al trasplante de tejido ovárico. Esta vez gracias a la Dra. Juana Crespo -IVI Valencia- y la Dra. María Sánchez -H.U. Pest Aleixandre-.

Esta breve introducción realizada respecto a los logros y éxitos que las técnicas de reproducción asistida consiguieron a lo largo de las últimas décadas, no es solo un homenaje a los equipos multidisciplinares que participaron, participan y participarán en ellas. Esta mirada retrospectiva demuestra que el ser humano es aún -hoy día- un gran desconocido para el hombre, y que gracias a la investigación pueden posibilitarse resultados que en el pasado hubieran sido inimaginables. Un claro ejemplo es el caso del nacimiento de hijos cuando los progenitores son infértiles.

Pero aunque en sus orígenes la aplicación de la reproducción asistida se utilizase con el único fin de paliar problemas de esterilidad, en la actualidad observamos que se añaden otros fines diversos. Es por ello que la vigente Ley 14/2006, de 26 de mayo, sobre técnicas de reproducción humana asistida, indique en su Exposición de Motivos que el objetivo de la aplicación de esta técnica no es solo la esterilidad, sino que contempla igualmente el diagnóstico -previo de enfermedades congénitas- y la investigación ${ }^{10}$.

compatibilidad existente de tejido orgánico entre dos personas. No todos los seres humanos somos histocompatible unos respecto a otros. Al

${ }^{9}$ La "anemia congénita severa" -también denominada esferocitosis hereditaria-, es una enfermedad genética de carácter hereditaria, que como consecuencia de la malformación de la membrana de los hematíes, estos se destruyen con gran facilidad en el bazo. Es conocida desde 1870, y se considera la anemia hemolítica hereditaria más común en la población humana.

${ }^{10}$ Exposición de motivos, Ley 14/2006 (párrafo 3): “....las técnicas de reproducción asistida, además de coadyuvar a paliar los efectos de la esterilidad, se manifiesta como especialmente útiles para otros fines, tales como los diagnósticos o de investigación". 
En los primeros años de aplicación de la FIV en España -principio de los 80`s-, la esterilidad o los problemas de fertilidad, motivaba que las parejas tradicionalmente compuestas por hombre y mujer, acudiesen a la ciencia biomédica para superar en la medida de lo posible sus problemas para procrear. Hoy -treinta y siete años más tarde-, podemos afirmar que los motivos que mueven a las personas para usar esta técnica han variado sustancialmente.

El fin de la investigación genética es en realidad una circunstancia colateral en relación a los usuarios de esta técnica. Para ellos la investigación no es el objetivo, sino una posibilidad que se les brinda en relación a la donación de células o tejidos que se necesitan para avanzar en las investigaciones biomédicas y en su caso, para obtener una información fidedigna que les permita tomar decisiones respecto a su reproducción. Sin embargo despierta un gran interés en científicos de la rama biológica y/o médica, y de manera más generalizada en la sociedad, como vía para la mejora de la reproducción y por ende de la salud humana.

Aunque coincidimos en afirmar que en sus inicios el usuario de la técnica FIV tenía como único objetivo engendrar un hijo, una vez conseguido el mismo, se escala un peldaño más en relación a la gran preocupación derivada por la incertidumbre de la salud del preembrión engendrado. Una salud que lógicamente no será buena si parte de alteraciones cromosomáticas o enfermedades hereditarias -hasta hace pocos años indetectables-.

Así el diagnóstico genético preimplantacional aparece con un peso específico tan importante o más que el de engendrar, procurar un embarazo viable o que se produzca el esperado nacimiento. ¿Por qué? Porque con ello se consigue detectar y evitar enfermedades genéticas, cuyos tratamientos en la actualidad son inexistentes. Dicho de otra manera, los usuarios de la técnica FIV hoy, no solo buscan engendrar y tener un embarazo viable, sino que esperan el nacimiento de un hijo sano. Es digno, humano y ético desde la posición del progenitor/a, querer lo mejor para su descendencia. Por ello si la biomedicina posibilita en la actualidad evitar enfermedades genéticas o enfermedades detectables que continúan sin cura, la norma jurídica deberá estar preparada para que los 
ciudadanos que opten por esta técnica, puedan tener la opción de llevarla a cabo con todas las garantías físico-médicas, psicológicas y jurídicas, en todo caso.

Dicho esto, parece razonable que el componente emocional de las personas vinculadas a la técnica FIV haya de ser tenida en cuenta por las regulaciones normativas actuales y futuras. Estas deben prever -y en su caso corregir- las situaciones de conflicto que puedan generarse tanto en los usuarios, como las consecuencias que consigo puedan derivarse de tal aplicación. Por ello nos encontramos ante un escenario en el que no solo aparecerán los usuarios de la técnica FIV. También habrá que pensar en el proceso y en las situaciones potencialmente diferentes que puedan surgir en cada caso en particular, para poder regular de manera general. Habremos de tratar este asunto desde un nítido punto de partida, por lo que los conceptos jurídicos preembrión, embrión, feto, y/o persona, deben quedar perfectamente delimitados, recordando que aunque el interés de este análisis biológico se centre en el estudio genético y en la congelación de los embriones humanos en reproducción asistida, las conclusiones que puedan derivarse sean aptas tanto desde una perspectiva biomédica como desde un punto de vista ético y por supuesto jurídico.

Así y antes de continuar profundizando en los conceptos jurídicos, debemos tener en cuenta la polémica creada en el marco constitucional español acerca de la personalización del embrión. El autor RUÍZ DE LA CUESTA indica respecto a la suscitada polémica, que "según la referida Declaración del Instituto Borja de Bioética, para considerar como persona al embrión humano, se deben cumplir determinadas condiciones biomédicas sin las cuales se podrá afirmar que hay vida humana, pero no una persona humana ${ }^{11 " .}$ Esas condiciones biomédicas las aclara indicando las mismas: " $1^{a}$ ) una constitución genética correcta desde el momento de la fecundación; $2^{a}$ ) que se den las condiciones de implantación que permitan hablar de individuación del embrión; $3^{\circ}$ ) que se dé una morfología mínima suficiente (estructura neurológica); $4^{a}$ ) que se produzca la circulación fisiológica materno-fetal o producción y circulación de elementos fisiológicos entre la madre y el embrión".

\footnotetext{
${ }^{11}$ Marco Jurídico Europeo relativo a la Investigación Biomédica en Transferencia Nuclear y Reprogramación Celular. Director: Daniel García San José. Thomson Reuters Aranzadi. Pamplona. 2012. Págs. 30-31.
} 
Se deduce de lo expuesto que quienes consideran al embrión humano como un ser humano desde el momento de su fecundación ${ }^{12}$-día primero o unión de gametos-, lo hace desde una "perspectiva exclusivamente biológica" sin tener en cuenta ningún otro factor como la intención -en su caso- de los padres para tener un hijo o la calificación moral que cada persona interprete en función del momento o del grado del desarrollo embrionario. Considerar al embrión humano como un completo ser humano -al menos jurídicamente-, equivaldría a negar el ya reconocido principio de progresividad del preembrión/feto, y el principio de preeminencia de la madre respecto al mismo, tal y como reconoce actual jurisprudencia en los tribunales internacionales, en referencia a estos asuntos.

A pesar de la existencia en nuestro país de regulaciones jurídicas que enmarcan precisamente el estatuto del embrión, continúan existiendo posturas divergentes al respecto. Así GARCÍA SAN JOSÉ, D. con gran acierto alude al "debate maniqueo planteado en torno al estatuto ontológico y ético del embrión humano ${ }^{13}$,", separando cuatro posicionamientos ontológicos ${ }^{14} \mathrm{y}$ tres éticos ${ }^{15}$. Un debate que debería enfrentarse desde una pluralidad de agentes y de perspectivas. Donde la Biología no sea la única base de interpretación y fundamentación que justifique la supremacía de unos derechos sobre otros, sino que sean tenidos en cuenta otros factores como la voluntad, las circunstancias personales, la libertad de opción, los derechos de los partícipes y sobre todo el respeto a las decisiones de quienes en última instancia habrán de asumir los deberes y obligaciones que de cada situación concreta se derive ${ }^{16}$.

\footnotetext{
${ }^{12}$ Es el caso de autores como MARINA RIOPEREZ, P., el cual discrepa con la postura de entender al preembrión humano como una condición de vida humana, pero no un ser humano. Él entiende que a pesar de que esta postura se ampare en la STC 53/1985, es precisamente contraria a ella, en relación al concepto "vida". Págs. 379-381. El jurista ante el trasplante de órganos humanos. Fundación Luis Portero. Granada. 2006.

${ }^{13}$ Marco Jurídico Europeo relativo a la Investigación Biomédica en Transferencia Nuclear y Reprogramación Celular. Director: Daniel García San José. Thomson Reuters Aranzadi. Pamplona. 2012. Págs. 285-286.

${ }^{14}$ Posicionarse respecto al embrión como a) persona, b) cosa, c) una realidad intermedia y d) posiciones agnósticas; si seguimos a BELLVER CAPELLA.

${ }^{15}$ Dándole diferentes valores éticos al embrión humano tal como a) tiene el valor de una persona, b) carece de cualquier valor, c) es un objeto merecedor de una tutela especial por parte del Derecho.

${ }^{16}$ Es fácil apoyar una tesis proteccionista en la cual el embrión está por encima de la madre o incluso la pareja, si se obvia completamente cualquier aspecto que no sea puramente biológico. La diversidad y pluralidad social nunca fue tan expresa y tan reconocida como en estos tiempos de globalización, donde "lo absoluto", "lo bueno" o "lo malo", es inexistente. Más bien las tesis deberán tender a asumir la flexibilidad y la pluralidad de situaciones y circunstancias, en función del momento temporal en el que nos encontremos, y respecto de la sociedad concreta sobre la que se trate.
} 
En todo caso la Ley 14/2006, de 26 de mayo, sobre técnicas de reproducción humana asistida, ofrece por primera vez en la regulación española definiciones nítidas sobre los siguientes conceptos. Comencemos con el de preembrión. La Exposición de Motivos II indica textualmente que “....el concepto de preembrión, entendiendo por tal al embrión in vitro constituido por el grupo de células resultantes de la división progresiva del ovocito desde que es fecundado hasta 14 días más tarde”. Luego el preembrión es la unión de un gameto femenino y uno masculino, que comienza a dividir sus células hasta el día 14 como máximo. Un año más tarde la Ley 14/2007 de 3 de julio, de Investigación biomédica, recogería esta definición de manera exacta para incorporarla a su capítulo de Definiciones $^{17}$.

¿Qué entendemos por embrión? La RAE tiene varias acepciones entre las cuales destaca: "1. Ser vivo en las primeras etapas de su desarrollo, desde la fecundación hasta que el organismo adquiere las características morfológicas de la especie. 2. En la especie humana, producto de la concepción hasta fines del tercer mes de embarazo. 4. Principio no desarrollado de algo." La RAE considera embrión a lo producido tras la fecundación, llegando este hasta el tercer mes de gestación. Sin embargo jurídicamente se ha necesitado diferenciar el concepto embrión y así la Ley 14/2007, de 3 de julio, de Investigación Biomédica, se diferencia en cuanto a los plazos, indicando en su artículo 3 -Definiciones-, apartado 1) que embrión se denomina a la "fase del desarrollo embrionario que abarca desde el momento en el que el ovocito fecundado se encuentra en el útero de una mujer hasta que se produce el inicio de la organogénesis, y que finaliza a los 56 días $^{18}$ a partir del momento de la fecundación, exceptuando del cómputo aquellos días en los que el desarrollo se hubiera podido detener." Esto último alude expresamente a los preembriones que quedan en "pausa" por criogenización. O dicho de otro modo, no los considera embriones cuando están en esta circunstancia de "stand-by". En este caso el embrión es denominado preembrión y jurídicamente habrá de tratarse como tal. Con esta comparativa se observa cómo jurídicamente se considera embrión hasta la semana octava de gestación, y en el caso de la RAE se considera hasta la semana duodécima.

\footnotetext{
${ }^{17}$ Artículo 3. Definiciones. Apartado s).

${ }^{18}$ Equivale a 8 semanas de gestación.
} 
¿Cómo define la RAE al feto? Indica que es el "embrión de los mamíferos placentarios y marsupiales, desde que se implanta en el útero hasta el momento del parto." Si esta definición indica que el embrión es el que anida hasta finalizar el tercer mes de gestación, a partir de ese momento y hasta su nacimiento habrá de ser denominado feto. Sin embargo la Ley 14/2007, de 03 de julio, lo define en su art. 3.n) como: "embrión con apariencia humana y con sus órganos formados, que va madurando desde los 57 días a partir del momento de la fecundación, exceptuando del cómputo aquellos días en los que el desarrollo se hubiera podido detener, hasta el momento del parto." Una vez más la norma define jurídicamente un concepto biológico para evitar confusiones. No es a partir de las 12 semanas de gestación -o tercer mes-, sino a partir de las 8 semanas -o segundo mes- hasta el momento del parto. La congelación de embriones detiene el tiempo de los mismos provocando una parada técnico-real en la progresividad biológica y por tanto jurídica. Por ello -y así se entiende con la actual normativa-, se tendrán en cuenta esos tiempos de crioconservación como no transcurridos a efectos biológicos ni jurídicos.

Con la Ley 14/2007 se han resuelto -entre otras cuestiones- las fronteras que delimitan los conceptos embrión y feto. La falta de rigor técnico en las redacciones normativas previas a la misma -o la omisión de términos biomédicos-, provocó una serie de conflictos jurídicos cuya resolución era reclamada a través de recursos de amparo, al entender que se podían violar derechos fundamentales de la persona. La entrada en vigor de la Ley 14/2007, de 3 de julio, de Investigación Biomédica, iluminó situaciones que hasta entonces el TC no lograba resolver, precisamente por la ambigüedad temporal en la que tanto el embrión como el feto, se hallaban inmersos jurídicamente.

Observamos así algunas sentencias del TC -anteriores a la citada ley- en las que actualmente su lectura pierde gran parte de su fundamentación jurídica. Es el caso de la STC 212/1996, de 19 de diciembre ${ }^{19}$, en la que se indica textualmente: “...en el texto articulado de la Ley no se defiende con claridad qué se entiende por embrión y feto, lo que vulnera el principio de seguridad jurídica en temas de tan alta trascendencia En el articulado de la Ley se distingue entre embriones y fetos a efectos de su distinta protección y de permitir la investigación o experimentación sobre ellos, pero sin que en ningún momento se establezca cuándo debe entenderse que se produce el paso del embrión al

\footnotetext{
${ }^{19}$ BOE núm. 19, de 22 de diciembre de 1997.
} 
feto; la distinción entre ambos, sin embargo, puede ser tan seria como la que se deduce del art. 5,apartado 3 y 4, pues los embriones abortados son objeto de una especie de presunción de no viabilidad mientras que los fetos son acreedores de tratamiento con fines de favorecer su desarrollo. Delimitados jurídicamente ambos conceptos, hoy sí puede aplicársele la presunción de no viabilidad a los embriones, y el tratamiento cuyo fin es el de favorecer su desarrollo a los fetos.

Superados los conflictos respecto a la nomenclatura y sus significados, jurídicamente "la personalidad se adquiere en el momento del nacimiento con vida, una vez producido el entero desprendimiento del seno materno" -art. 30 del Código Civil-. Dicho de otra manera, no se adquiere la capacidad de ser persona jurídica hasta que el feto nace vivo, y lo hace de manera autónoma fuera del vientre materno. Caso de nacer muerto, no sería por tanto considerado persona jurídica como tal -con independencia de los sentimientos y emociones que pudieran tenerse hacia el mismo-. Es pacífico afirmar que las normas jurídicas son positivas, y como tal debe encuadrarse de manera concisa tanto las calificaciones de los objetos dignos de protección, como sus derechos -especialmente en referencia al estatuto del embrión-.

Para fundamentar conclusiones con una mínima solidez, hemos de analizar ahora quiénes son las personas que participan en la técnica FIV, a través de la Ley 14/2006, de 26 de mayo, sobre Técnicas de Reproducción Humana Asistida. Esta cuestión se responde en el Capítulo II Participantes en las técnicas de reproducción asistida -art. 5 al art. 10 ambos inclusive-. Observemos cada una de las posibles personas "partícipes" en la aplicación de la técnica in vitro y sus denominaciones. Para ello es necesario aclarar previamente algunas circunstancias que -francamente- son desconocidas por gran parte de la población civil, incluyendo en esta a profesionales del ámbito jurídico, médico, biológico, etc., simplemente por falta de especialización en su ámbito profesional, o llegado el caso, por la falta de ánimo para enfrentarse a cuestiones éticas que provocan dudas existenciales en la propia persona.

Dado que la propia Ley reconoce que la fecundación in vitro es una técnica que ha evolucionado mucho en los últimos años, y que no solo permite solucionar los problemas de esterilidad sino también "permite evitar - en ciertos casos- la aparición de 
enfermedades, en particular en las personas nacidas que carecen de tratamiento curativo", habremos de tener en cuenta que hay personas/parejas fértiles desde la perspectiva físico-biológica, que no necesitan usar la citada técnica para procrear. Sin embargo en ellas se dan situaciones ${ }^{20}$ en las que se obtienen resultados ${ }^{21}$ que avocan en una descendencia cuyas enfermedades son en muchos casos incurables e incompatibles con la vida humana ${ }^{22}$. Este es el caso de las aneuploidias ${ }^{23}$. En principio cualquier pareja heterosexual que pretenda procrear es susceptible de esta técnica, máxime cuando tengan antecedentes familiares aneuploides, por lo que es aconsejable realizar estudios genéticos previos. Por ello en principio, cualquier hombre o mujer podría ser usuario $^{24}$ potencial de esta técnica.

Sin embargo la Ley 14/2006, de 26 de mayo, en su Artículo 6.1 -Usuarios de las técnica- indica lo siguiente: "Toda mujer mayor de 18 años y con plena capacidad de obrar podrá ser receptora o usuaria de las técnicas reguladas en esta Ley, siempre que haya prestado su consentimiento escrito a su utilización de manera libre, consciente y expresa". Es decir que los usuarios de FIV son definidos como las mujeres receptoras: la mujer a la que se le implanta el preembrión. La mujer que va a gestar. Inicialmente puede llamar la atención la ausencia de la figura masculina en la no inclusión del artículo 6.1., pues nadie duda que se necesite un gameto masculino para fecundar uno femenino ${ }^{25}$. Pero la redacción de la Ley procura dar una clara definición -y lo consigue-, nombrando como

\footnotetext{
${ }^{20}$ Por ejemplo la limitación biológica respecto a la edad fértil de la mujer.

${ }^{21}$ La significación de "resultado" en ningún caso habrá de entenderse como un "producto terminado", como nos encontramos en algunos escritos. Denominación desafortunada donde las haya, dado que entendemos como "resultado" el objetivo -si no sueño- cumplido de ser padres: de conseguir un embarazo.

${ }^{22}$ Es el caso de las trisomías 18 (Síndrome de Edwards), trisomía 13 (), Trisomía 9 (), hipofosfatasia congénita, condrodisplasia punctata, osteogénesis imperfecta tipo II, acondrogénesis, displasia tanatofórica, Síndrome de bandas amnióticas, pentalogía de Cantrell, hidranencefalia, etc.

${ }^{23}$ La aneuploidía es la anomalía cromosómica -y por tanto genética- más frecuente en los seres humanos. Aparece con forma de trisomía o monosomía.

${ }^{24}$ Ser usuario -o potencial usuario- de la técnica FIV en España, no implica ni la obligación ni el deber jurídico de aplicarla en los casos que existan enfermedades genéticas, ya sea por antecedentes familiares o por historial clínico personal. Es una opción -legítima- que se ofrece como alternativa al problema citado, y que en todo caso puede ser aplicada o no en función de la voluntad de los posibles usuarios. Es una libertad de opción la que se ofrece al ciudadano: (i) estudiar previamente los preembriones para evitar enfermedades genéticas y/o irreversibles o incurables, o (ii) dejar al azar la posibilidad transmitir dichas enfermedades por motivos religiosos, morales o simplemente por desconocimiento de las posibilidades que esta técnica ofrece actualmente.

${ }^{25}$ En biología puede denominarse al gameto masculino como aquel material biológico imprescindible para llevar a cabo el proceso de fecundación, junto al gameto femenino.
} 
usuaria a la mujer que recibirá en su seno al preembrión. La distingue entre el resto de partícipes o posibles partícipes.

El art. 6.5 -Usuarios de las técnicas-, de la Ley 14/2006 cita al donante de semen. ¿Cuál es el fin de diferenciar a la usuaria del resto de personas potencialmente partícipes? Precisamente la respuesta es la "potencialidad" de las circunstancias que pueden darse en FIV, ya que con la fijación de estas nomenclaturas, se posibilita regular una casuística bastante amplia. Como claro ejemplo basta citar la pluralidad de formas en las que el preembrión puede llegar a conformarse: (i) por inseminación en fresco del semen de la pareja -o marido- de la usuaria, (ii) por donación de gametos masculinos -o esperma-, (iii) por descongelación de semen, etc. Así comprendemos que la única persona que siempre se repetirá en el proceso de FIV es la usuaria: la persona a la que se le implantará definitivamente el preembrión.

Tras el paso de algo más de una década desde la proclamación estas leyes, echamos de menos que no se exponga la plural casuística en cuanto a la vinculación de la usuaria y la persona con la que va a realizar la reproducción asistida -en su caso-, a través de la inclusión de parejas estables. Sirva este artículo para sensibilizar acerca del reconocimiento expreso de cualesquiera circunstancias personales, dado que la circunscripción de la misma Ley 14/2006, puntualiza escasa y expresamente tan solo una de las situaciones potenciales dentro de las relaciones de la usuaria. Citar como referente la figura civil del matrimonio, equivale a regular para solo una parte de la sociedad. La realidad se impone y lo que deberíamos regular en todo caso, son las parejas con relación estable -casadas o no-. La Ley se empobrece y minimiza su versatilidad desde el momento en el que se redacta sobre un limitado espectro de relaciones: “...si la mujer estuviera casada ....”. El contenido de la norma debería ser más amplio respecto a los vínculos de pareja.

El estado civil de las personas en cuanto a su vinculación matrimonial, no exime a las parejas de hecho inscritas - $\mathrm{O}$ no- a ser sujetos dignos de las mismas protecciones jurídicas y por tanto dignas de mención en la norma positiva. Los deseos de procreación en los casos de una pareja no se fundamentan ni justifica a través del vínculo matrimonial, sino a través del ejercicio de las libertades personales de cada uno de los individuos. Desde el punto de vista bioético tienen reconocido un mismo tratamiento, aunque jurídicamente y 
sin embargo, se sufre una discriminación subyacente en las parejas sin vínculo matrimonial, respecto a las matrimoniales.

Dos personas mayores de edad y con capacidad de obrar, pueden libremente optar por esta técnica con independencia de su estado civil -matrimonial o no-, hasta el punto de que en ningún caso podrá exigírsele a los mismos ningún tipo de certificado que justifique o declare jurídicamente su relación y/o compromiso personal. ¿Debe pedirse permiso al Estado o a las AAPP -en su caso- para engendrar un hijo? La respuesta es obvia: no. En ese caso se agradecería un tratamiento jurídico inocuo y aséptico al respecto, simplemente por respeto a la diversidad de relaciones actuales existentes. El matrimonio es un vínculo jurídico que en ningún caso puede servir de escala de medir para seccionar o minusvalorar otros tipos de relaciones y vinculaciones tanto en pareja estables como en las familias que como tal, $\operatorname{son}^{26}$.

Es más, la usuaria podrá asumir sola y sin pareja engendrar un hijo, por lo que la donación de esperma será su opción. En el contrato de donación ${ }^{27}$ se indicará de forma expresa la renuncia a cualquier tipo de derecho - presente o futuro- respecto su objeto. Por supuesto este tipo de donaciones habrán de cumplir unos mínimos requisitos jurídicos como la gratuidad -art. 618 CC-, formalidad -art. 632 CC-, e irrevocabilidad-arts. 644 y ss.-, teniendo en cuenta que "podrán hacer donaciones todos los que puedan contratar y disponer de sus bienes" -art. 624 CC-, y "podrán aceptar donaciones todos los que no estén especialmente incapacitados por la ley para ello" -art. 625 CC-. En todo caso y como indica LASARTE ÁLVAREZ, “aunque el Código no lo califica como contrato, sino como acto, y la regula con ocasión de los modos de adquirir la propiedad, el carácter contractual le viene dado por la exigencia de la aceptación por parte del donatario (art. 630), lo que supone el acuerdo de los dos contratantes y, de otra parte, por la sujeción a

\footnotetext{
${ }^{26}$ Con independencia de que posean -o no- un "libro de familia". En muchos casos sirve únicamente como prueba administrativa de las relaciones formalizadas jurídicamente.

${ }^{27}$ Según el art. 618 CC se define contrato de donación como "el acto de liberalidad por el cual una persona dispone gratuitamente de una cosa en favor de otra, que la acepta". Una de las características necesarias para la perfección de dicho contrato, es la "aceptación", art. 623 CC. La usuaria en estos casos no acepta sino que espera y desea una donación de este tipo para poder engendrar.
} 
otras disposiciones generales de los contratos y obligaciones en todo lo que no se halle determinado en sus normas específicas (art. 621)",28.

A pesar de lo expuesto el art. 6.3 de la Ley 14/2006, de 26 de mayo hace referencia al estado civil matrimonial: "Si la mujer estuviera casada, se precisará, además, el consentimiento de su marido, a menos que estuvieran separados legalmente o de hecho y así conste de manera fehaciente. El consentimiento del cónyuge, prestado antes de la utilización de las técnicas, deberá reunir idénticos requisitos de expresión libre, consciente y formal". Por supuesto entenderemos que la Ley 14/2006, de 26 de mayo, sobre técnicas de reproducción humana asistida, al ser posterior a la Ley 13/2005, de 01 de julio, por la que se modifica en Código Civil en materia de derecho a contraer matrimonio, ha de adaptarse a esta última. Por ello el matrimonio en la ley de técnicas FIV habrá de entenderse $-\mathrm{a}$ todos los efectos- como matrimonio heterosexual u homosexual, con la consecuente variedad de casos posibles que puedan darse en la aplicación de esta técnica. Antiguas relaciones que ven su reconocimiento y consolidación jurídica en estos nuevos tipos: matrimonios o parejas estables hombre-hombre, mujer-mujer, mujer-hombre.

Sin entrar en debates éticos que consideramos socialmente superados, puede afirmarse que en parejas homosexuales compuestas por dos mujeres ${ }^{29}$, se generan varias opciones de fecundación in vitro, las cuales habrán de ser tenidas en cuenta en el momento las redacciones normativas. En el caso de las parejas homosexuales formadas por varones no hay disyuntiva posible, pero en el caso de parejas mujer-mujer, si lo hay. Teniendo en cuenta que la usuaria es la que gestará finalmente llegado el caso, pueden darse las siguientes situaciones:

a) Que la mujer gestante sea la que aporta su propio gameto -inseminado artificialmente por donación de esperma-, por lo que la otra mujer no aporta material genético ni espacio vital para la gestación.

b) Que la gestante sea receptora de un preembrión, cuyo gameto femenino haya sido recibido a través de una donación, no siendo este de su pareja -mujer-.

\footnotetext{
${ }^{28}$ Contratos. Principios de Derecho Civil III. Autor: Carlos Lasarte. Editorial Marcial Pons. Vigésima edición. Madrid. 2018. Pág. 176.

${ }^{29}$ El art. 6 de la Ley 14/2006, exige como únicos requisitos a las mujeres para ser receptora o usuarias, ser mayor de 18 años y tener plena capacidad de obrar, siempre que el consentimiento se preste "de manera libre, consciente y expresa”.
} 
c) Que la gestante reciba de su pareja -mujer-, el gameto necesario para ser implantado a través de la FIV. En este caso las dos mujeres aportan: la gestante su cuerpo para gestar, y la otra mujer su gameto femenino. Ambas participan biológicamente en estos casos -epigénesis-.

Hasta hace tan solo unas décadas y en referencia al último de los casos expuestos, podríamos afirmar que el conflicto ético en este tipo de relaciones -mujer/mujer-, no abría puertas a la consideración de que ambas pudieran tener un justo título como "madres". Primero habría de llegar el cambio y avance ético en la sociedad, y más tarde habrá de llegar el jurídico, como ocurre en cualquier sociedad desarrollada y en orden. Pero ostentar el reconocimiento social de que ambas sean "madres" -del tan esperado bebé-, no es comparable con la ausencia de datos biomédicos y/o genéticos que brillaban por su ausencia hasta hace relativamente pocas décadas.

Los avances en investigación genética por parte de biólogos como Waddington ${ }^{30}$ en los años cuarenta del pasado siglo XX, suman avances en el conocimiento del ser humano, separándose así dos puntos de vista totalmente divergentes: la doctrina que defiende que la genética es la base única de los caracteres y cambios que conforman al ser humano y este trasmite por herencia a sus descendientes, y la doctrina que afirma que la genética es solo una parte de la formación del ser humano, habiendo de tener en cuenta en dicha formación biológica, fenotipos distintos y por qué no, caprichos -aún poco conocidos- de la materia orgánica en general, y del ser humano en particular.

Pues bien, la respuesta bajo nuestro punto de vista respecto a considerar si son o no madres biológicas en la situación del caso c) mujer/mujer, entendemos que se responde y resuelve no solo con la ayuda de la Genética y la Biología, sino con la Epigenética $^{31}$.

Hasta hace relativamente pocos años, la genética y su estudio ${ }^{32}$ era un campo de trabajo e investigación puramente médico. Concretamente los especialistas eran genetistas.

\footnotetext{
${ }^{30}$ Conrad Hal Waddington, fue un biólogo escocés - genetista y embriólogo-, el cual es considerado uno de los padres de la Epigenética. Nacido en 1909 y fallecido en 1975, se graduó en Geología en la Universidad de Cambridge, cursando con posterioridad estudios de paleontología, hasta llegar a la inducción embrionaria en mamíferos.

${ }^{31}$ La RAE hace referencia al concepto epigenético como "perteneciente o relativo a la epigénesis", definiendo así el término epigénesis como la "doctrina según la cual los rasgos que caracterizan a un ser vivo se configuran en el curso del desarrollo, sin estar preformados en el huevo fecundado".
} 
Sin embargo Aristóteles (384-322 A.C.) propugnaba la epigénesis como una forma de desarrollo de los embriones animales, llegando a ser campo de investigación en especial para los biólogos. Así encontramos a investigadores como Conrad Hal Waddington, el cual es considerado como el padre de la Epigenética, al integrar la genética con la embriología y a su vez la evolución de estos ${ }^{33}$. También es destacable el bioquímico Joseph Needham quien -junto a Waddington-, intentó investigar en bioquímica y junto a la genética del desarrollo, un proyecto en un centro interdisciplinario, el cual fue rechazado finalmente por la universidad de Cambridge.

La investigadora sobre mecanismos epigenéticos Denisse Barlowen, en 2006 hizo la siguiente declaración: "la Epigenética son todas las cosas extrañas y maravillosas que no pueden ser explicadas por medio de la genética". Aunque académicamente pueda resultar "romántica" dicha definición, habremos de interpretarla como que en la actualidad existen una serie de vacíos de conocimiento, que aun estando por descubrir, están. Más adelante haremos mención a una serie de análisis -DGP y test NACE-, los cuales nos permiten hoy día conocer la genética humana desde una cercanía inimaginable hasta hace tan solo unas décadas. Adelantamos así que el conocido como test NACE es una prueba fidedigna que confirma el hecho de que las células de los hijos se queden durante años en el cuerpo de la madre a través de su torrente sanguíneo, por lo que puede afirmarse que existe intercambio de células y/o tejidos entre ambos, detectables a partir de la semana diez de embarazo -con independencia de que finalmente sea o no viable el mismo-. Siendo esto así, ¿dudamos aún de que la mujer que recibe el óvulo de su pareja -mujer-, tenga vinculación biológica desde el mismo momento de la implantación? ¿Solo se transmiten caracteres biológicos genéticos? Parece que la respuesta ha de ser negativa, y por tanto la Epigenética es una parte muy importante a tener en cuenta en relación a la formación biológica del ser humano.

Sin perder de vista y avanzando en la línea de la Ley 14/2006, decíamos que el Artículo 5 Donantes y contratos de donación, hace una mención expresa de las personas físicas que potencialmente pueden participar en la FIV. "Potencialmente" porque la

\footnotetext{
${ }^{32}$ Llevado a cabo únicamente por genetistas hasta aproximadamente 1942, momento en el que Waddington biólogo-, comenzó a interesarse por la genética.

${ }^{33}$ De la Genética a la Epigenética. La herencia que no está en los genes. Autores: De la Peña, Clelia; Loyola, V.M. Editorial FCE- Fondo de Cultura Económica. Primera edición electrónica, 2017. Pág. 162.
} 
donación no es estrictamente necesaria en todos los casos de infertilidad o problemas de fecundación. Pero de ser necesaria dicha donación -en la actualidad de gametos ${ }^{34}$ y/o preembriones ${ }^{35}$-, el o los donantes, son una parte fundamental en el proceso reproductivo.

En el caso de los/las donantes de gametos y/o preembriones ${ }^{36}$, el planteamiento de las regulaciones normativas habrá de tener en cuenta los Derechos Fundamentales y Civiles de cada uno de los partícipes, a la par que deberán tener en cuenta con los continuos e inminentes avances biomédicos y/o tecnológicos, procurando una flexibilidad normativa que permita a la misma adecuarse sin tener que modificar o derogar continuamente las mismas ${ }^{37}$. Así llegados a este punto habremos de fijarnos en el sujeto donante.

La STC 11/1981, de 8 de abril, expresa que la Constitución Española representa "un marco de coincidencias suficientemente amplio como para que dentro de él quepan opiniones políticas de muy diferente signo”. El art. 9.2 de la CE indica básicamente que les corresponde a los poderes públicos la promoción de las condiciones para que la libertad y la igualdad de los individuos se integren de manera real y efectiva, removiendo aquellos obstáculos que impidan o que dificulten la plenitud o facilidad de participación de los ciudadanos, ya sea en la vida política, cultural, económica o social. Y el art. 10.1 CE -de los derechos y deberes fundamentales-, cita textualmente: "la dignidad de la persona, los derechos inviolables que le son inherentes, el libre desarrollo de la personalidad, el

\footnotetext{
${ }^{34}$ Debe entenderse por "gameto", aquella célula reproductora femenina o masculina, de un ser vivo. En los seres humanos es imprescindible para poder crear una persona.

${ }^{35}$ El concepto "preembrión" ha sido motivo de posturas jurídicas -doctrinales- muy opuestas, por lo que la Ley 14/2007, de 3 de julio, de Investigación biomédica, tuvo la necesidad de definirla en su art. 3 para -al menos- partir de un concepto concreto y nítido, desprovisto de cualquier tipo de duda. Así el citado artículo lo expone como la fase de desarrollo embrionario, desde el momento de la fecundación hasta el día catorce.

${ }^{36}$ La donación de gametos puede ser de dos tipos: femenino -óvulo-, o masculino -espermatozoide-. Una mujer puede recibir una donación de esperma usando su propio óvulo, pero se dan casos en que es conveniente recibir un óvulo donado sin necesidad de recibir donación de semen -como es el caso de tener pareja-. Igualmente en lugar de recibir una u otra donación por parte de uno u otro gameto, puede ser necesario recurrir a la donación de preembrión. Esto conlleva que la usuaria recibe donado un preembrión, cuyo origen es la unión de un gameto femenino y otro masculino, procedente de una pareja que decide no utilizarlo para sí, ni para investigación, y sí para que puedan ser implantados en personas con problemas de fertilidad.

${ }^{37}$ Exposición de motivos, Ley 14/2006 (párrafo 10): “.....La nueva Ley sigue un criterio mucho más abierto al enumerar las técnicas que....pueden realizarse hoy. Sin embargo, evita la petrificación normativa y habilita a la autoridad sanitaria correspondiente para autorizar,.... la práctica provisional y tutelada como técnica experimental de una nueva técnica."
} 
respeto a la ley y a los derechos de los demás son fundamento del orden político y de la paz social".

La dignidad, los derechos inviolables inherentes al individuo y el libre desarrollo de la personalidad, son fundamentos más que suficientes para el reconocimiento jurídico respecto a la donación de materiales biológicos procedentes del cuerpo humano ${ }^{38}$. No obstante y partiendo en última instancia desde el respeto a la ley, se vuelve a fundamentar y reconocer el derecho a las técnicas de reproducción asistida ${ }^{39}$, a la autonomía del paciente y de sus derechos y obligaciones en materia de información y documentación clínica $^{40}$, o al establecimiento de normas de calidad y seguridad sobre la donación de células y tejidos humanos ${ }^{41}$-entre otras-. La libertad personal es en definitiva un derecho constitucionalmente protegido, y por ello la donación de gametos y/o preembriones es amparado por las leyes españolas. Así puede afirmarse que “...existe una conexión entre el derecho de libertad y la dignidad de la persona pues en aquella descansa el desarrollo y aprecio por la persona misma. Igualmente es correcto decir que la idea de dignidad está sujeta, como todo valor, a la percepción social que de ella se tenga en cada época, ${ }^{, 42}$.

El análisis del donante de gametos y/o preembriones, nos obliga inexorablemente a analizar su material biológico -humano- desde una perspectiva patrimonial, en el ámbito del derecho Civil. Así como expone LASARTE ÁLVAREZ, "la propiedad queda consagrada como un poder absoluto de la persona sobre la cosa, que se concreta, primordialmente, en las facultades de goce y disposición "43, la cuestión debe partir en este asunto en el reconocimiento -o no- del propio cuerpo, como cosa susceptible de gozar y disponer del mismo, con plena o limitada libertad. En caso de postular en defensa del cuerpo como propiedad patrimonial de la persona al que se le reconocen derechos de goce

\footnotetext{
${ }^{38}$ Células, tejidos, órganos.

${ }^{39}$ Ley 14/2006, de 26 de mayo, sobre técnicas de reproducción humana asistida.

${ }^{40}$ Ley 41/2002, de 14 de noviembre, básica reguladora de la autonomía del paciente y de derechos y obligaciones en materia de información y documentación clínica.

${ }^{41}$ Real Decreto-ley 9/2014, de 4 de julio, por el que se establecen las normas de calidad y seguridad para la donación, la obtención, la evaluación, el procesamiento, la preservación, el almacenamiento y la distribución de células y tejidos humanos y se aprueban las normas de coordinación y funcionamiento para su uso en humanos.

42 GONZALO HERRANZ, Eutanasia y dignidad del morir. Vivir y morir con dignidad: Temas fundamentales de Bioética en una sociedad plural. Coord.: Elena Postigo Solana. EUNSA 2002. Págs. 173190.

${ }^{43}$ Compendio de Derechos Reales. Derechos reales e hipotecario. $7^{\text {a }}$ Edición. Marcial Pons. Madrid. 2018.
} Pág. 2. 
y disposición del mismo, habría que analizar si estos derechos están limitados desde el ámbito civil, precisamente por los límites inherentes al concepto de propiedad. Según el mismo autor “...en sentido estricto, por limitación de la propiedad se ha de entender aquella reducción que encuentra causa en una disposición legal expresa; establecida por tanto, con independencia de la voluntad del propietario y en atención a las necesidades planteadas por la convivencia social, ya sean las llamadas limitaciones por razón de interés público....ya por el interés privado" ${ }^{\text {.44 }}$.

En referencia a la titularidad y la disposición de los materiales biológicos humanos, cabe indicar que el principio de la autonomía privada aporta cada vez más solidez y garantías jurídicas a la voluntad. Si bien no es motivo de discusión considerar que ser titular de un derecho real implica la potestad sobre bienes cuya posición económica podrá interesar a la sociedad en general -sin que esta pueda aprovecharse de ellos al estar afectados por un derecho de propiedad enmarcado en una persona individual-, tampoco habrá de ser motivo de conflicto afirmar que "el derecho de propiedad envuelve el disfrute de su valor económico que queda a la voluntad de la persona si aprovecha el valor de los bienes de los que es propietario" 45 .

Siguiendo en la línea del Derecho civil patrimonial, este persigue un orden en las relaciones entre individuos cuyo fin es evidentemente práctico -e incluso económico-, respecto de los bienes o cosas que regula. Tanto el concepto propiedad como el de dominio, se matizan a lo largo de los actos de disposición que sobre estos se realizan. Por ello en relación a los materiales biológicos que proceden del ser humano ${ }^{46}$, a pesar de no tener una regulación expresa como bien patrimonial, parece relativamente aceptado y superado que el cuerpo humano es de la persona que lo ocupa, lo posee y lo disfruta en todas sus vertientes posibles: ya sea física o corpóreamente.

La biomedicina, a través de los avances científicos y tecnológicos que se desarrollan en la actual y globalizada sociedad, nos hace partícipes de nuevos modos de

\footnotetext{
${ }^{44}$ Compendio de Derechos Reales. Derechos reales e hipotecario. $7^{\text {a }}$ Edición. Marcial Pons. Madrid. 2018. Pág. 2.

${ }^{45}$ ACEVEDO RODRÍGUEZ, en su obra "Titularidad y disposición de los materiales biológicos procedentes del cuerpo humano. Estudio comparado entre España, Estados Unidos y Puerto Rico", analiza las facultades del titular natural y las limitaciones como derecho subjetivo, respecto al material biológico de la persona. Pág. 91.

${ }^{46}$ Células, tejidos u órganos.
} 
concebir el cuerpo. Dicho de otra manera nos presenta nиеvos usos sobre el cuerpo, que no tienen una regulación específica ad hoc, o incluso no pueden hallarse en disposiciones previas y explícitas en nuestro Código Civil.

En el caso general de las donaciones -y desde el más puro ámbito civil-, partimos de un negocio jurídico en el que solo el propietario de la cosa y/o el derecho, puede realizar tal uso y disposición de traslación de dominio, sin olvidar que la característica esencial del mismo, es su gratuidad. En el caso de la donación de gametos y/o preembriones, nos encontramos ante un tipo muy particular de donación, el cual ha generado diferentes y enfrentadas posturas éticas en función de la naturaleza de la misma. Considerar el cuerpo humano como patrimonio de la persona en los tiempos actuales, es una realidad que no tiene objeto de discusión. Y no la tiene porque de hecho encontramos regulación específica al respecto ${ }^{47}$, y por ello no podemos indicar que la ley sea un límite precisamente para la aplicación del derecho a usar, disfrutar y disponer de nuestros gametos y -en su casopreembriones.

El artículo 5.1 de la Ley 14/2006, de 26 de mayo, sobre técnicas de reproducción humana asistida, define la donación de gametos y preembriones como un contrato gratuito, formal y confidencial. Como acertadamente expone ACEVEDO RODRÍGUEZ sobre la plasticidad que actualmente tiene el derecho de propiedad respecto a la revolución que actualmente provocan las llamadas ciencias vivas: "No existe una normativa que incluya un catálogo pormenorizado de cada una de las facultades que el ordenamiento reconoce a la persona física...en la praxis, la facultad del goce alude al valor en uso de la cosa, comprendiendo tanto la utilización directa del bien como la indirecta; mientras de otra parte la facultad de disposición supone la materialización del valor en cambio del bien, siendo su reflejo prototípico la facultad de transmitir la tenencia del derecho de propiedad a un tercero a cambio o no de precio" ${ }^{48}$. Es evidente que es extrapolable la situación de donación de gametos y preembriones a esta circunstancia de reconocimiento patrimoniopersonal, donde la transmisión concreta de tales derechos reales, habrán de conformarse en

\footnotetext{
${ }^{47}$ La Ley 35/1988, de 22 de noviembre, del Registro de donantes de gametos y preembriones con fines de reproducción humana, es un antecedente jurídico que reconoce tácitamente el derecho de propiedad -desde el ámbito jurídico civil- del cuerpo, respecto al ser humano que lo habita.

48 "Titularidad y disposición de los materiales biológicos procedentes del cuerpo humano". Acevedo Rodríguez, Nidia. Edit. Dykinson, S.L., 2017. Madrid. Págs. 92-93.
} 
nuestro derecho español a través de la figura expresa de la donación, o si se quiere, del contrato de donación.

La insistencia tanto en relación a las denominaciones jurídicas cuanto a las específicas regulaciones de derechos fundamentales -derechos constitucionales- o derechos de propiedad -derechos civiles-, han de fundamentarse en la necesidad inminente de solventar algunos conflictos nacidos de la aplicación de la norma sobre reproducción asistida: los límites éticos en el uso y disfrute final de los preembriones cuando no existe un expreso consentimiento de donación de los mismos.

Subrayando las concretas características del contrato de donación aplicable en el caso de gametos y preembriones por la Ley 14/2006 -gratuito, formal y confidencial-, es destacable conocer el procedimiento por el que la donación de preembriones en última instancia -y a pesar de ser regulado por la citada ley-, deja un potencial espacio en el que dependiendo de circunstancias tácitas -que no expresas-, el fin de los embriones puede llegar a ser donados a un tercero ${ }^{49}$, sin el expreso consentimiento de los donantes. Dicho de otro modo, se donan a otras parejas o usuarias, preembriones congelados sin el expreso consentimiento de los que aportaron sus gametos y/o preembriones para uso propio.

Estando en disposición de analizar los problemas que está conllevando la aplicación de las actuales legislaciones -acumulación de miles de preembriones que se hallan en un limbo jurídico y ético-, planteamos antes una realidad con la que se convive y debe tenerse en cuenta. ¿Cualquier persona es apta o susceptible para ser usuaria o donante?

Expresa la ley que la usuaria o receptora de la técnica de reproducción asistida ha de ser mayor de edad y tener plena capacidad de obrar -art. 6.1 Ley 14/20016-. Sin embargo sobre los donantes de gametos y/ o preembriones -se entiende-, el art. 5.6 de la Ley 14/2006 indica que "habrán de tener más de 18 años, buen estado de salud psicofísica y plena capacidad de obrar". No existe ninguna limitación de edad expresa en relación a quienes pueden o no ser usuarias o donantes. Sin embargo en la realidad nos encontramos con situaciones en las que hay usuarias que quieren serlo a partir de una edad en la que difícilmente se les ofrecerá la posibilidad en nuestro Estado español. De hecho existe una

\footnotetext{
49 En definitiva los "centros autorizados" citados por la Ley 14/2006: centros sanitarios y equipos biomédicos.
} 
franja de edad en la mujer - cada vez más común-, en la que volver a ser madre es una opción no solo legítima, sino posible.

Cada vez son más las mujeres que posponen la maternidad por diferentes motivos ${ }^{50}$, y ello no debe crear un menosprecio o minusvaloración a este tipo de decisiones personalísimas. Todo lo contrario si se tiene en cuenta que la decisión es realizada por una mujer madura, con una situación normalmente más estable que la de mujeres más jóvenes, y en las que a pesar del trabajo, los hijos previos en su caso, la tenencia de una pareja con quien compartir ese hijo -o no-, etc., no restan ilusión a tener este nuevo o posterior hijo. La maternidad se está posponiendo cada vez más -es una realidad-, y el límite de edad no está regulado -ni debe estarlo-. Lo que sí se entiende o se desprende de la lectura de la ley, es que además de ser mayor de edad y tener plena capacidad de obrar, ha de tener una situación física y psíquica adecuada para todo el proceso reproductivo, hasta llegar al momento del esperado nacimiento.

Pero nos encontramos con una realidad que desdobla las posibilidades de estas mujeres que quieren ser madres a partir de los 40 años. Hasta esta edad -hasta que no cumple cuarenta años-, la mujer puede llevar a cabo un proceso reproductivo de este tipo siempre que se aseguren los equipos médicos que los intentos han sido fallidos durante un periodo aproximado de un año, o de conseguir finalmente embarazos, estos no llegan a ser viables. Tanto la sanidad pública como la privada atienden a este tipo de mujeres con problemas de fertilidad. Sin embargo a partir de los 40 años esto se convierte realmente en una odisea en España.

En la actualidad la sanidad pública aplica un límite de edad en las mujeres de 40 años y en los hombres de 55. Teniendo en cuenta que cada vez somos más longevos, ¿no deberíamos tener en cuenta que quizás la naturaleza del hombre y la mujer está cambiando a pesar de que sus cuerpos cumplan años y el envejecimiento sea inexorable?

En la sociedad española actual llevamos viendo durante años, cómo las familias están cambiando: no solo han aumentado los divorcios, sino que han aumentado el número de familias que se recomponen tras los mismos. Cada vez es más común que tras un

\footnotetext{
${ }^{50}$ Artículo Maternidad y Fertilidad. Diario El País. 24.09.2018. Autora: LEÓN, M.. Profa Ciencias Políticas. Univ. Autónoma Barcelona.
} 
divorcio o ruptura de pareja, ambas partes se recompongan emocionalmente, construyendo a partir de nuevas relaciones de pareja, nuevas familias. Estas nuevas parejas en muchas ocasiones desean tener hijos comunes, aportando a la relación un nuevo hijo, con independencia de que uno de ellos o ambos, tengan hijos nacidos de relaciones anteriores. En la mayoría de estos casos nos encontramos con familias que se reestructuran partiendo de una cierta edad. ¿Cómo puede negarse a una mujer que quiere tener un hijo a partir de los 40 años en nuestro país, que pueda llegar a ser madre con cierta seguridad, llegado el caso de que sus intentos al gestar se vean frustrados? En estos casos en España, habrá de recurrirse a la sanidad privada. No queda otra alternativa.

Así llegamos a encontramos ante una tesitura ético-jurídica al considerar biológicamente aptas o no aptas para ser madres, a las mujeres a partir de los cuarenta años. ¿Quién lo decide? ¿Qué tercera persona y bajo qué criterios decide si una mujer es apta o no para ser madre a partir de la edad biológica de cuarenta años? La respuesta jurídica enfoca directamente a los equipos médicos y a los centros autorizados para esta práctica. Claro está que los equipos médicos nada tienen que decir en la sanidad pública, teniendo en cuenta las limitaciones impuestas - sin ser expresas en la ley- es de 55 años para los hombres y 40 para las mujeres. En este caso la sanidad pública deja fuera a este tipo de mujeres y o familias, cuya única opción viable para ser madres es la de acudir a la sanidad privada.

¿Qué diferencias hay entre sanidad pública y privada respecto a los requisitos que se consideran han de cumplir estas mujeres o usuarias? Partiendo de la inexistencia de límite de edad en la ley, depende precisamente de los equipos médicos y/o de los centros autorizados. En España es generalizado por casi todas las clínicas privadas, establecer una edad máxima en la mujer de 49 a 50 años para poder ser madre por fecundación invitro, siendo la edad del hombre un asunto secundario, pues dependerá más la calidad seminal que de la edad del mismo. En todo caso siempre está la opción de recibir donación de semen, por lo que la usuaria tiene hasta estas edades para poder gestar por FIV. En el caso de mujeres que han querido ser madres con más edad, estas han tenido que desistir, optar por viajar fuera de nuestras fronteras a buscar equipos médicos que las consideren madres 
potenciales, o encontrar esos equipos médicos que sí ven viabilidad en la usuaria, pese a su edad. Es el caso de Lina Álvarez ${ }^{51}$, la cual tuvo una hija con 62 años.

Aquí surge un debate añadido que surge de la economía personal: el derecho a ser madre $-\mathrm{O}$ no- en función de si se tiene el poder adquisitivo suficiente para optar a un proceso que es caro, y que por muchos adelantos biomédicos que existan, hay probabilidades razonables de no llegar a conseguir embarazos viables. Al caso de mujeres en edad avanzada ${ }^{52}$, se les presupone una economía saneada e incluso más que suficiente para afrontar esos gastos. No profundizaremos en esta presunción por ser demasiado generalista con las mujeres, y porque no es el fin de este estudio. Pero en rigor es necesario admitir y/o reconocer que jurídicamente en la actualidad, las mujeres españolas mayores de cuarenta años que tienen problemas para procrear -o cuando lo hacen tienen alto riesgo de engendrar con aneuploidías-, tienen un tratamiento negativamente discriminatorio respecto a las que son más jóvenes. La situación se complica en muchos casos cuando la mujer pospone por motivos laborales y/o profesionales, el momento para ser madre ${ }^{53}$.

Si la biotecnología permite a las mujeres ser madres cada vez a edades más avanzadas, y estas tienen a su vez una salud mejor que en tiempos pasados, habremos de replantearnos esta situación desde otras perspectivas. Por ejemplo teniendo en cuenta que las mujeres dejan de ser madres jóvenes por motivos principalmente económicos y laborales. A este respecto el Estado debería tomar medidas, generando políticas reales y efectivas donde el hecho de ser madre no sea un sueño inalcanzable, permitiendo a las mujeres-madres que se desarrollen tanto en el ámbito personal como en el laboral, dejando de ser una utopía o en su caso, perdiendo oportunidades profesionales con la excusa no solo de la maternidad, sino por el hecho de ser madres: título que se adquiere con el nacimiento de los hijos, y que se desea mantener durante toda la vida.

\footnotetext{
${ }^{51}$ Lina Álvarez es una gallega -de profesión médico-, la cual tuvo a su primer hijo a los 34 años. Una mala praxis en la amniocentesis dejó con una parálisis cerebral a su primer hijo. A los 52 años -9 años más tarde de que la menstruación se le retirase-, una clínica privada -La Esperanza de Santiago de Compostela-, a través de una FIV con embrión de pareja donante, tuvo a su segundo hijo. El tratamiento le costó entonces 6.000 $€$,lo cual ha sido su verdadero límite al plantearse ser madre de nuevo: su economía mermada. Tras buscar tratamientos en EEUU, encontró una clínica en Madrid - no reveló cual-, que a sus 62 años ha hecho posible que pudiera tener su tercera hija.

${ }^{52}$ Consideraremos al grupo de mujeres mayores de 40 años.

${ }^{53}$ Es el caso de la famosa alpinista española Edurne Pasaban, que por motivos puramente profesionales y gracias al consejo profesional de su médico, se extrajo óvulos y los congelaron, cuando estaba en una edad límite en fertilidad -38 años-. A los 43 años ha sido madre por primera vez tras largos tratamientos de fertilidad -no siempre fructíferos-, y así la alpinista disfruta hoy de su primer hijo junto al padre del mismo.
} 
Se tiene asumido que el tiempo es un factor fundamental en la mujer $-\mathrm{y}$ en su salud $^{54}$ - respecto a su capacidad para engendrar. Médicamente ha de tenerse en cuenta no solo el deseo de tener un hijo, sino los riesgos médicos -y también jurídicos- que pueden ocasionarse en cada caso concreto. Sin embargo a partir de los 40 años de edad -cuando se dispara el porcentaje de abortos y de aneuploidías ${ }^{55}$-, a pesar y quizás por ese riesgo médico, no se ofrecen alternativas en la sanidad pública a las parejas o usuarias. La única alternativa en fecundación -más segura que el soñado embarazo natural-, es la sanidad privada. No se tiene en cuenta que los embarazos naturales a partir de los 40 años trae consigo estadísticamente un elevado número de abortos naturales o embarazos con aneuploidías -algunas de ellas incompatibles con la vida humana como el Síndrome de Edwards-. Estos embarazos naturales a su vez generan en el sistema sanitario público una serie de costes dignos de ser tenidos en cuenta. Quizá debamos plantear que el Estado sea paternalista en estos casos, pues desde un punto de vista puramente económico, el hecho de realizar FIV a pacientes de más de 40 años, evitará a la sanidad pública tener que costear las nefastas repercusiones que se sufren muchas mujeres tras múltiples intentos fallidos respecto a engendrar un hijo: abortos, legrados, ingresos hospitalarios, bajas laborales, tratamientos por ansiedad, depresión, etc.

Teniendo en cuenta que la sanidad privada amplía la edad de las mujeres que buscan un embarazo viable, unos diez años más que la sanidad pública, ¿cuáles son los límites que la sanidad pública española aplica para ser aptos/as para fecundaciones in vitro? Podrían resumirse en ocho, teniendo en cuenta que las CCAA tienen competencia al respecto y por lo tanto puede variar de una a otra. Serían las siguientes:

$1^{\circ}$.- La edad límite para las mujeres son 40 años, y para los hombres 55 años.

$2^{\circ}$.- Es necesario que se dé una incapacidad para lograr concebir, por lo que habrán de someterse a varias pruebas de fertilidad.

\footnotetext{
${ }^{54}$ Así autores como GARAY, A., se preocupa tanto por el riesgo médico como por el riesgo jurídico, indicando que el riesgo médico es un "riesgo operacional" que se basa en el riesgo jurídico. Dice que "no se trata de analizar el procedimiento médico desde una perspectiva clínica, sino de saber cómo actuar con el Derecho para minimizar el riesgo médico desde el marco de las normas jurídicas, reguladoras y sancionadoras". (Gestión Jurídica del riesgo. Autor: Alain Garay. CTO Editorial. Madrid. 2013. Págs. 7-8.

${ }^{55}$ Las "aneuploidías" aparecen en un 5\% aproximadamente en todos los embarazos clínicamente reconocidos, y la mayoría de estos mueren en el útero. Es clínicamente la principal causa genética de pérdida de embarazos.
} 
$3^{\text {o. }}$ - Si se tienen hijos en común, no se ofrece esta alternativa en la seguridad pública, exceptuando los casos en los que el hijo padezca una enfermedad de carácter crónica diagnosticada. En el caso de que uno solo de los miembros de la pareja tenga hijos, sí se podrá optar a FIV.

$4^{\text {o }}$.- Si no se aconsejase usar el esperma del cónyuge varón, se procederá a usar muestras seminales de donaciones privadas. Ocasionalmente se permite la congelación de esperma como ocurre en los casos en el que el hombre ha de someterse a tratamientos oncológicos, y previamente se extrae y congela para su posterior tratamiento.

$5^{\circ}$.- Las CCAA tienen competencias normativas para regular el número de ciclos máximos a los que se pueden acoger las parejas, siendo lo más generalizado que en FIV sean tres ciclos a lo sumo, cuatro inseminaciones artificiales como máximo -si es esa la opción de tratamiento-, o seis intentos si la inseminación es con semen de donante.

$6^{\circ}$.- Los pacientes que sufran enfermedades como VIH o Hepatitis C -además de otras graves de transmisión hereditaria-, no serán aptos en FIV en la sanidad pública o sufrirán muchos obstáculos en su caso para que la alternativa pública sea posible.

$7^{\circ}$.- Dentro del tratamiento de reproducción asistida existen algunas pruebas las cuales no son cubiertas por la sanidad pública como son la ovodonación o el diagnóstico genético preimplantacional debido al coste tan elevado que estas pruebas tienen.

$8^{\circ}$.- Las parejas con diagnóstico de esterilidad son potenciales receptores de la técnica, pero en la actualidad no cubre tratamientos de fecundación ni de donación de gametos a las parejas homosexuales ni a las mujeres sin pareja.

Estas ocho pautas lógicamente son filtros que impiden asistir a muchas usuarias y donantes en la sanidad pública, por lo que solo podrán optar por la vía privada caso de disponer de recursos económicos suficientes para ello. Precisamente el séptimo filtro que limita la FIV pública señala al conocido como Diagnóstico Genético Preimplantacional o DGP, como uno de los requisitos que a pesar de ser necesario en algunos casos, no cubre la asistencia pública: se deniega $a b$ initio. Pero ¿Qué es el DGP?

Como en todo en la vida, las mejores definiciones las pueden ofrecer quienes mejor conocen esta técnica. Hay laboratorios especializados en reproducción asistida -públicos y 
privados-, y algunos de estos la definen de la siguiente manera: "El diagnóstico Genético Preimplantacional detecta y previene la transmisión a la descendencia de enfermedades graves causadas por alteraciones genéticas y cromosómicas en los embriones, antes de ser transferidos al útero, lo cual ayuda a evitar que nazcan bebés libres de enfermedades hereditarias. Dentro del DPI existen variantes según el tipo de problema a detectar. Hay muchos tipos de anomalías cromosómicas, pero podemos clasificarlas como numéricas o estructurales. Las anomalías numéricas tienen un cromosoma más o un cromosoma menos de lo que sería el par normal (23 pares de cromosomas), y las anomalías estructurales suceden cuando una parte de un cromosoma en particular falta, está de más, se ha pasado a otro o está invertida". 56

Decíamos que la técnica FIV permite a las personas con problemas para engendrar un hijo seno, poder llegar definitivamente a este objetivo. Conociendo el alcance tan potente que tiene el Diagnóstico Genético Preimplantacional, llegamos a la conclusión de que la detección precoz de enfermedades genéticas no mejora la técnica reproductiva de facto, sino que posibilitando por anticipado conocer los resultados genéticos, permite "tomar decisiones" que de no conocer a priori, acabarían con gran probabilidad, con el nacimiento de personas con graves problemas de salud: aneuploidías. La FIV se puede aprovechar de ese conocimiento exacto que aporta el DGP, para que las personas tomen con esta información la decisión de implantar o no el preembrión en el útero materno.

Hay posturas que se inclinan por afirmar que el DGP le quita naturalidad a la creación de un ser humano y que es una forma tecnológica e industrial de crear personas perfectas. No estamos de acuerdo en absoluto. Nuestros razonamientos son los siguientes:

(a) El preembrión en ningún caso puede ser considerado ser humano, aunque por supuesto requiera una protección especial. No es comparable su situación biológica ni jurídica con el de los embriones implantados, los fetos en seno materno o con la situación de persona nacida, desprendida del seno materno y viva;

(b) El análisis del preembrión da información, no se manipula genéticamente. Los bioquímicos y biólogos, solo exponen lo que ven, pudiendo tener la opción de elegir entre implantarlo por FIV -o no-, con conocimiento de la existencia o no de aneuploidías.

\footnotetext{
${ }^{56} \mathrm{https} / / /$ ivi.es/tratamientos-reproduccion-asistida/dgp-pgt/
} 
(c) No es una selección en el que se pueda elegir sexo, color de ojos o cualquier otra cualidad genética del preembrión. Su análisis determina únicamente la existencia o no de alteraciones cromosomáticas.

(d) No existe seguridad absoluta de que el preembrión que se decide implantar -sin aneuploidías estudiadas previamente-, se desarrolle bien en el útero materno, pues la salud, los hábitos y el entorno de la madre receptora, determinará con más o menos probabilidad llegar con éxito al momento del parto. La Epigenética es parte de la formación de embrión, el feto y la persona nacida en su caso.

(e) Tampoco puede asegurarse que llegado al fin deseado -un bebé- este sea completamente.... ¿normal? Puede ser que sea tartamudo, o tímido, o celíaco. No se crean personas perfectas. Se evitan malformaciones y enfermedades, pues si son evitables gracias a los niveles de biotecnología actuales, ¿qué mal o ilícito se surge de estas situaciones?

Gracias a la reproducción asistida hoy, se consiguen embarazos que de manera natural no serían posibles. Gracias al DGP se posibilita conocer la transmisibilidad -o node aneuploidías muy comunes como lo son el Síndrome Down (trisomía en cromosoma 21), Síndrome Edwards (trisomía en cromosoma 18), Síndrome de Patau (trisomía del par 13), Síndrome de Turner (45X), Síndrome de Klinefelter (47XXY), o los 47XYY y 47XXX (también llamados comúnmente sexuales). No es banal nombrar estas alteraciones o enfermedades genéticas, pues son las más comunes en el ser humano.

¿Quién querría tener un hijo que con toda probabilidad es gestado con problemas incompatibles con la vida, cuando con un simple análisis ${ }^{57}$ ya es posible? Estaremos de acuerdo en afirmar que todo ser humano quiere lo mejor para sus hijos. Lo primero que se les desea a estos es tener salud. Pues bien, precisamente este es el objetivo del DGP: comprobar y asegurarnos de que un preembrión -gametos femenino y masculino unidos con menos de 14 días-, es o no sano genéticamente. Con esta técnica se analiza y comprueba la correcta multiplicación de células en sus primeros días, posibilitando realizar

\footnotetext{
${ }^{57}$ En todo caso estos análisis no se ofertan en sanidad pública -excepto casos muy concretos y limitados-, por lo que las personas o parejas que no cumplen los requisitos exigidos hoy por la seguridad social -o pública-, han de inexorablemente tender a la contratación de estas analíticas, cuyo coste no está al alcance de cualquier persona de economía media.
} 
biopsias desde el tercer al sexto día, y así poder analizar sus 46 cromosomas. De este modo se comprueba la viabilidad de un preembrión o no.

De estos análisis y estudios sobre los preembriones, derivan informes muy sólidos y seguros respecto a la existencia o no de aneuploidías. Teniendo en cuenta que las aneuploidías aparecen en un 5\% aproximadamente de todos los embarazos clínicamente reconocidos, y añadiendo la información de que la mayoría de estos embriones y/o fetos mueren en el útero, puede afirmarse que esta es clínicamente la principal causa genética de pérdida de embarazos ${ }^{58}$.

Reconozcamos así que este sistema tan precoz -DGP- funciona perfectamente como método informativo de los resultados obtenidos sobre los preembriones analizados, en tan solo unas semanas. Dado que desde que se realiza en laboratorio la unión de gametos -fecundación- hasta poder biopsiarlos hay un periodo aproximado que oscila de 3 a 6 días, y teniendo en cuenta que el diagnóstico genético tarda unos 12-14 días en tener resultados, nos encontramos ante un preembrión que podría llegar a tener 20 días para obtener su información genética, con lo cual nos excederíamos del plazo que la ley marca como máximo para ello: 14 días. Por este motivo una vez biopsiados los embriones $-\mathrm{y}$ a la espera de conocer los resultados respecto a su viabilidad o no-, deben congelarse, quedando a la espera de los resultados del DGP para tomar la decisión de si queremos que se implanten o no: de descartar los aneuploides y quedarnos con los genéticamente sanos.

Existen otros sistemas de detección de las aneuploidías que se desarrollan en un periodo embrionario o fetal -no preembrionario-, desde la semana 10 de gestación, como lo es el análisis sanguíneo NACE ${ }^{59}$-o test NACE-. La diferencia más llamativa entre el DGP y el análisis NACE, es que aunque ambos basan su eficacia en localizar aneuploidías existentes, en el caso del DGP se produce en un momento anterior a la transferencia al útero -en laboratorio-, mientras que el análisis NACE se realiza en un momento posterior

\footnotetext{
${ }^{58}$ Artículo de investigación firmado por Terry Hassold y Patricia Hunt. Department of Genetics, Case Western Reserve University, 10,900 Euclid Avenue, Cleveland, Ohio 44106, USA. www.nature.com/reviews/genetics. April 2001, Volume 2

${ }^{59}$ El test NACE se realiza a partir de la semana 10 de embarazo, a través de la extracción de una muestra de sangre materna, el cual y gracias a los avances en biomedicina y biotecnología, recoge muestras epiteliales del feto que circulan por el torrente sanguíneo de la madre, y que solo a partir de estos tiempos -no antes-, es posible analizar. Se estima en 20 años la duración que las células de los hijos engendrados, perduran en el cuerpo de la madre a través de su torrente sanguíneo.
} 
-durante el primer trimestre de embarazo-, a través de una sencilla extracción de muestra de sangre de la madre. Parece que sobra explicar la diferencia entre uno y otro análisis, dado que son "momentos" muy diferentes en la madre, tanto biológica como emocionalmente. Un ejemplo en el que sería conveniente realizar un TCG entre ambas partes -gameto masculino y femenino por separado-, es el caso de personas cuyos antecedentes familiares han padecido aneuploidías. Sin embargo esta es una cuestión que solo es amparada por la sanidad privada en España.

Los juristas no debemos hacer oídos sordos a los avances médicos y biológicos, y hemos de conocer -entre otras muchas cuestiones-, que dos gametos por separado "sanos" pueden devenir en el momento de la división celular en un preembrión enfermo ${ }^{60}$. Luego el azar o capricho de la naturaleza será también una cuestión digna de ser tenida en cuenta en el momento de regular. Por ello cuando mencionábamos las palabras que Denisse Barlowen citaba en 2006 sobre "las cosas extrañas y maravillosas que no pueden ser explicadas por medio de la genética" -en referencia a la Epigenética-, habremos los juristas que entender y procurar adaptar las normas con la mayor de las humildades posibles, ante lo que cada vez es "menos desconocido".

Así autores como GARCÍA SAN JOSÉ, en sus observaciones concluyentes ${ }^{61}$ nos indica tras investigar y analizar las diferentes normativas y los objetivos en investigaciones sobre clonación humana y embriones humanos en Europa, que el conjunto de dichas normas son pésimos. Normas jurídicas que no confluyen ni tienen un mínimo de homogeneidad entre los distintos Estados de la Unión Europea. Lo cual nos hace reflexionar ante la gran labor que el jurista tiene en España y en Europa, aún.

Todo lo expuesto puede parecer a priori que no crea ningún tipo de conflicto ético ni jurídico, pero existe una situación que ha quedado en el aire y debemos tenerla en cuenta.

Una vez congelados los preembriones de una pareja -imaginemos que cuatro sin aneuploidías-, se usa uno para implantarse y conseguir un embarazo. En muchas ocasiones,

\footnotetext{
${ }^{60}$ Es el caso de la Trisomía de Edward, la cual no se produce hasta el momento de la fecundación, aproximadamente entre el segundo y tercer día.

${ }^{61}$ European Normative Framework for Biomedical Research in Human Embryos. Editorial Thomson Reuters Aranzadi. Navarra. 2013. Págs. 161-162.
} 
tras el nacimiento de hijos, o incluso tras decidir no continuar con el proceso FIV -por agotamiento emocional y físico-, quedan embriones congelados en las clínicas o centros de fertilidad. ¿Qué ocurre con ellos? Según el art. 11.4 de la Ley 14/2006, los destinos posibles tanto de gametos como de preembriones crioconservados, son cuatro: (1) su utilización por la propia mujer o su cónyuge; (2) la donación con fines reproductivos; (3) la donación con fines de investigación; y (4) el cese de su conservación sin otra utilización.

En el primer caso consideraremos que la mujer o su cónyuge ${ }^{62}$ ya han hecho uso de ellos y los que quedan, no los van a usar para nuevos embarazos, luego descartamos esta opción, pero siguen congelados estos preembriones. En el segundo y tercer caso, la ley posibilita donarlos con dos tipo de fines distintos: para la investigación y para fines reproductivos -en otras parejas con problemas para engendrar-. En gran cantidad de ocasiones las parejas no quieren compartir, no quieren donar sus preembriones crioconservados, ni para la ciencia -por motivos éticos y personales-, ni para otras parejas - por crearles un conflicto interno a uno o a ambos, respecto al hecho de donar a otros la genética de ambos. Totalmente respetable y así es reconocido por la ley. Pero continuamos con los preembriones congelados y como último destino, se indica el cese de su conservación sin otra utilización. En este último caso y si no se ha optado por alguno de los tres anteriores, la ley prevé su destrucción siempre y cuando se agote el periodo fértil de la mujer ${ }^{63}$ receptora, y esto se acredite mediante un informe médico ajeno al centro donde se encuentren crioconservados los preembriones. Es fácil imaginar que muy pocas personas optan por esta vía teniendo en cuenta que han de aportar un certificado médico, etc. En todo caso, este límite atañe aproximadamente a un tercio de los preembriones congelados. ¿Qué hacemos con el resto? Continuemos avanzando.

El art. 11.5 de la Ley 14/2006, indica que en cualquiera de los 4 fines citados por la misma, se "requerirá del consentimiento informado correspondientemente debidamente acreditado". Muchas parejas ante la duda de si querrán tener más hijos un poco más adelante, también descartan esta opción. Se quedan congelados "por si acaso queremos

\footnotetext{
${ }^{62}$ Expresión que habremos de interpretar como pareja estable, y no exclusivamente como matrimonio.

${ }^{63}$ El periodo fértil de la mujer es un concepto jurídico indeterminado, el cual debe formalizarse en cada caso concreto y específico, siendo los equipos médicos los que han de tomar la decisión de considerar o no apta a la mujer, para tales fines, en un momento concreto de su vida. Es frecuente que las clínicas privadas tengan un límite general establecido de 49 a 50 años. Pero podrían entender-y dar viabilidad- a mujeres cuyo periodo fértil ha terminado, pero consideran aptas para poder gestar y ser madres, a pesar de tener edades avanzadas.
} 
tener más hijos en el futuro". Así los preembriones se acumulan criogenizados en los centros sanitarios habilitados para ello, y los cónyuges continúan sin indicar nada al respecto a pesar de que la Ley exige que el consentimiento en cualquiera de ellas, sea expreso.

El art. 11.6 que indica cada dos años -como mínimo-, en el caso de los preembriones se solicitará a la mujer o pareja, el "consentimiento" para la modificación de su estado. Dice el mismo artículo que "los preembriones quedarán a disposición de los centros en los que se encuentren crioconservados, que podrán destinarlos conforme a su criterio a cualquiera de los fines citados, manteniendo las exigencias de confidencialidad y anonimato establecidas y la gratuidad y ausencia de ánimo de lucro". Sin embargo y a pesar de la regulación, esa comunicación se rompe en gran número de ocasiones por traslados de vivienda, cambio de número de teléfono, por dejadez, despiste u olvido de la mujer o las parejas respecto de sus preembriones congelados. A veces incluso por el propio conflicto que les crea a estos tener que tomar una decisión tan personal.

¿Qué se hace en estos casos, que además son cada vez más numerosos? Acabamos de observar que el art. 11.6 de la Ley 14/2006 transmite en estas circunstancias la disposición de los preembriones, a los centros en los que se encuentren crioconservados, y su destino final será los que estos centros estimen oportunos. Esta es la cuestión más delicada, aunque regulada jurídicamente: el conflicto ético que surge al posibilitar fines respecto de los preembriones, que en todo caso la mujer o pareja "no ha consentido expresamente en trasladar su dominio, uso o posesión a otros. Concretamente a los citados centros.

Llegados a este punto nos planteamos la siguiente cuestión: en caso de que el centro no pueda contactar con la mujer o pareja, en caso de simple despiste humano de olvidar que tengo que consentir cada dos años, en caso de un cambio de datos personales o de contacto que no se actualice correctamente, o en cualquier otro caso en el que transcurran más de dos años y los centros "adquieran" esos preembriones para "cualquier uso":

- ¿Es éticamente aceptable que los centros donen a otras parejas estos preembriones? 
- ¿Es éticamente asumible que haya centros que "donen” estos embriones a la ciencia o a otras parejas sin el expreso consentimientos de la mujer o pareja en cuestión?

- ¿Podrían devenir estas "adquisiciones derivadas de silencios administrativos", en un reclamo para que algunos centros se lucren a través del incremento de número de FIVs?

- ¿Podría descontrolarse el número de hermanos/as genéticos en una misma zona geográfica con las consecuencias biológicas que esto pudiera traer consigo?

- En este último caso si se comenzase a intercambiar con otros centros estos preembriones para evitar malformaciones genéticas, ¿podría entenderse que existiría tráfico comercial de preembriones?

La respuesta a cada una de estas cuestiones nos provoca un nuevo replanteamiento de la Ley 14/2006 en relación al artículo 11. Creemos necesaria una nueva redacción del artículo, pues en cualquier caso la libertad para elegir la FIV como alternativa para engendrar a un ser humano -a un hijo- dentro de los límites legales, en ningún caso debería permitir que un preembrión humano quede a disposición de cualquiera que no sean los titulares del mismo, sin una donación expresa.

Entendemos que en la actualidad la Ley permite "donaciones inducidas" sin conocimiento expreso de los donantes, siendo estas contrarias no solo al propio Código Civil español, sino a la ética tanto de los titulares legítimos ${ }^{64}$, como de los profesionales que dirigen los centros que reciben -hoy- estos preembriones para destinarlos a lo que estimen oportuno. No estamos de acuerdo en absoluto. Esperemos que esto se corrija en

\footnotetext{
${ }^{64}$ SÁNCHEZ PATRÓN, J.M., en la obra compartida Bioderecho, Seguridad y Medio Ambiente (Tirant Monografías 989, Valencia 2015, Pág. 47-48), expresa en parte de sus conclusiones lo siguiente en referencia a la prevalencia de la protección de la madre: "El examen de la jurisprudencia internacional relativa al derecho a la vida y el alcance de la protección jurídica del no nacido ha permitido deducir una serie de principios en los que sintetizarse la interpretación y aplicación del más fundamental de los derechos a los casos vinculados con el inicio de la vida humana.....Aunque los tribunales internacionales mantienen divergencia acerca del momento en el que debe iniciarse la protección jurídica del ser humano, existe coincidencia en considerar que esta va a ser progresiva en función del desarrollo del embrión/feto, no alcanzando mayor grado de protección hasta que se produzca el momento del nacimiento del individuo (principio de progresividad)....Fuera de los supuestos en los que la jurisprudencia internacional ha reconocido una protección exclusiva del embrión, este posee -incluso cuando ha evolucionado a feto-, una protección subsidiaria con respecto a la reconocida a la madre que lo gesta. Con carácter general, la madre dispone de una protección preeminente sobre el feto así como sobre terceras personas relacionadas con éste último". Si existe esta protección preeminente de la madre sobre el embrión o feto, ¿cómo se permite su donación para transferir a otras parejas o mujeres, sin el debido y ético consentimiento expreso?
} 
IUS ET SCIENTIA (ISSN 244-8478) 2019, Vol. 5, nº 1, pp. 54-89 EMBRIONES EN REPRODUCCIÓN HUMANA ASISTIDA: CONTROVERSIAS SOBRE LA CONGELACIÓN Y EL ESTUDIO GENÉTICO PRE-IMPLANTATORIO, Patricia CRAVIOTTO VALLE, Universidad de Sevilla, pcraviotto@us.es

Recibido: 18/10/2018. Aceptado: 16/05/2019 DOI: http://doi.org/10.12795/IESTSCIENTIA.2019.i01.03

breve y no se confunda el término libertad con otros términos como el consentimiento. Si los titulares no indican nada tras ser comunicados o no pueden indicar nada por no ser localizados -o haber fallecido-, entendemos que estos tendrán un periodo limitado en el que habrán de ser destruidos o en todo caso, donados a la investigación. Pero en ningún caso deberían ser donados a otros receptores por "silencio".

Autora: $\quad$ Patricia Craviotto Valle

Área temática: Ciencias biomédicas, bioética y derechos civiles. Controversia: congelación y estudio genético pre-implantatorio de los embriones en FIV.

Palabras claves: Preembriones. Criogénesis. Diagnóstico Genético Preimplantacional. Maternidad. Fecundación in vitro. Aneuploidías.

Key words: $\quad$ Pre-embryos. Cryogenesis. Preimplantation Genetic Diagnosis. Maternity. In vitro fertilization. Aneuploidies.

Resumen: $\quad$ La reproducción asistida en humanos es un asunto delicado desde la perspectiva biomédica, social y jurídica. La biotecnología permite hoy analizar los embriones humanos a través del estudio genético, además de congelarlos para poder tomar decisiones sobre los mismos, pasado un tiempo, y con información veraz sobre posibles 
IUS ET SCIENTIA (ISSN 244-8478) 2019, Vol. 5, nº 1, pp. 54-89

EMBRIONES EN REPRODUCCIÓN HUMANA ASISTIDA: CONTROVERSIAS SOBRE LA

CONGELACIÓN Y EL ESTUDIO GENÉTICO PRE-IMPLANTATORIO, Patricia CRAVIOTTO VALLE, Universidad de Sevilla, pcraviotto@us.es

Recibido: 18/10/2018. Aceptado: 16/05/2019 DOI: http://doi.org/10.12795/IESTSCIENTIA.2019.i01.03

enfermedades genéticas. La ley española deja vacíos legales. Vamos a analizarlos.

Abstract:

Assisted reproduction in humans is a delicate issue from a biomedical, social and legal perspective. Biotechnology allows today to analyze human embryos through genetic study, in addition to freezing them to be able to make decisions about them, after a time, and with accurate information about possible genetic diseases. The Spanish law leaves legal gaps. Let's analyze them.

\section{Bibliografía:}

- Abellán Salort, J.C. Fines y límites del Estado: paternalismo y libertades individuales. Universidad Francisco de Vitoria. Madrid. Anuario jurídico y Económico Escurialense XXXIX (2006) 363-384 / ISSN: 1133-3677.

- Acevedo Rodríguez, Nidia. Titularidad y disposición de los materiales biológicos procedentes del cuerpo humano. Estudio comparado entre España, Estados Unidos y Puerto Rico. Editorial Dykinson, S.L. Madrid. 2017.

- Boladeras, M. Bioética: La toma de decisiones. Editorial Proteus. $1^{\text {a }}$ edición: octubre 2011.

- De la Peña, Clelia; Loyola, V.M. De la Genética a la Epigenética. La herencia que no está en los genes. Editorial FCE- Fondo de Cultura Económica. Primera edición electrónica, 2017.

- Garay, A. Gestión Jurídica del Riesgo Médico. CTO Editorial. Madrid. 2013.

- García San José, D. European Normative Framework for Biomedical Research in Human Embryos. Editorial Thomson Reuters Aranzadi. Navarra. 2013.

- García San José, D. (Director). Marco Jurídico Europeo Relativo a la Investigación Biomédica en Transferencia Nuclear y Reprogramación Celular. Editorial Thomson Reuters Aranzadi. Pamplona. 2012. 
IUS ET SCIENTIA (ISSN 244-8478) 2019, Vol. 5, nº 1, pp. 54-89

EMBRIONES EN REPRODUCCIÓN HUMANA ASISTIDA: CONTROVERSIAS SOBRE LA

CONGELACIÓN Y EL ESTUDIO GENÉTICO PRE-IMPLANTATORIO, Patricia CRAVIOTTO VALLE, Universidad de Sevilla, pcraviotto@us.es

Recibido: 18/10/2018. Aceptado: 16/05/2019 DOI: http://doi.org/10.12795/IESTSCIENTIA.2019.i01.03

- Lasarte Álvarez, C. Compendio de Derechos Reales. Derechos Reales e Hipotecario. Editorial Marcial Pons. $7^{\text {a }}$ Edición. Madrid. 2018.

- Lasarte Álvarez, C. Contratos. Principios de Derecho Civil III. Editorial Marcial Pons. Vigésima edición. Madrid. 2018. Pág. 176.

- Marina Riopérez, P. El Jurista ante el Trasplante de Órganos Humanos. Régimen Jurídico Administrativo. Fundación Luis Portero. Granada. 2006.

- Sánchez Patrón, J.M. Bioderecho, Seguridad y Medioambiente. Editorial Tirant lo Blanch. Monografías. 989. Valencia. 2015.

\section{Referencias:}

- http://www.tahefertilidad.es/37-anos-de-avance-continuo-la-historia-de-lareproduccion-asistida-en-fechas/

- http://www.scielo.edu.uy/scielo.php?script=sci_arttext\&pid=S168803902016000300011

- www.nature.com/reviews/genetics

- https://informalia.eleconomista.es/informalia/actualidad/noticias/8801801/12/17/La -alpinista-Edurne-Pasaban-rescata-los-episodios-mas-tragios-de-su-vida

- https://www.igenomix.com/es/test/test-prenatal-no-invasivo-nace/

- https://elpais.com/elpais/2018/09/24/opinion/1537786323_009164.html

- www.avantiafertilidad.com/es/publicaciones-en-las-que-hemos-participado/libroblanco-sociosanitario-la-infertilidad-en-espana-situacion-actual-y-perspectivas 